\title{
AVALIAÇÃO DO RENDIMENTO EM MADEIRA SERRADA DE Eucalyptus benthamii E DE Eucalyptus grandis POR MEIO DO DESDOBRO TANGENCIAL E RADIAL
}

\author{
Alexsandro Bayestorff da Cunha ${ }^{1}$, Morgana Cristina França ${ }^{2}$, Caio César Faedo de Almeida ${ }^{2}$, \\ Luciane Gorski ${ }^{2}$, Rodrigo Coelho da $\mathrm{Cruz}^{3}$, Dalton dos Santos ${ }^{3}$ \\ ${ }^{1}$ Universidade do Estado de Santa Catarina, Departamento Engenharia Florestal, Lajes, Santa Catarina, Brasil - a2abc@cav.udesc.br \\ ${ }^{2}$ Universidade do Estado de Santa Catarina, Programa de Pós-Graduação em Engenharia Florestal, Lages, Santa Catarina, Brasil - \\ morganaa_franca@ hotmail.com; caio-almeida@florestal.eng.br; lu_gorski@hotmail.com \\ ${ }^{3}$ Klabin S.A., Otacílio Costa, Santa Catarina, Brasil - rodrigocoelhodacruz@ hotmail.com; daltonsantos10@hotmail.com
}

Recebido para publicação: 28/06/2013 - Aceito para publicação: 13/05/2014

\begin{abstract}
Resumo
O objetivo foi determinar o aproveitamento do Eucalyptus benthamii e do Eucalyptus grandis no processo de desdobro. A metodologia envolveu duas classes diamétricas (20-25 cm e 25,01-30 cm) e dois sistemas de desdobro (tangencial e radial). O rendimento do desdobro foi obtido pela relação entre o volume de toras e o de madeira serrada, sendo separado em bruto, sem rachaduras, sem destopo e líquido. Na análise do rendimento, adotou-se a Análise da Variância e o Teste de Tukey. Os resultados encontrados demonstraram que o sistema de desdobro tangencial apresentou melhor aproveitamento da matéria-prima. Os tratamentos compostos pelo E. benthamii e sistema tangencial foram os que apresentaram maior redução no rendimento em função da retirada das partes rachadas das peças, enquanto que, para a perda devida ao destopo, as porcentagens encontradas foram equivalentes para ambas as espécies. No rendimento final do processo, houve uma redução do rendimento em madeira serrada, com o aumento do diâmetro das toras para as duas espécies. Palavras-chave: Eucalipto; rachaduras de topo; aproveitamento da matéria-prima; serraria.
\end{abstract}

\begin{abstract}
Evaluation of the yield in sawnwood of Eucalyptus benthamii and Eucalyptus grandis by tangential and radial sawing. The aim was to determine the yield of Eucalyptus benthamii and Eucalyptus grandis in the process of the sawing. The methodology involved two diameter classes $(20-25 \mathrm{~cm}$ and $25.1-30 \mathrm{~cm}$ ) and two systems sawing (tangential and radial). The yield of sawing was obtained through the relationship between the volume of logs and lumber, being separated into gross yield, no splits, no trimming and liquid. The analysis yield was adopted the Analysis of Variance and Tukey test. The results demonstrated that the system of tangential sawing showed better utilization of rawmaterial. The treatments consisted of the E. benthamii and tangential system presented the greatest yield reduction due to the removal of parts of the split pieces, while for the loss due to destopo, the percentages found were similar for both species. In the final yield of the process, there was no reduction of yield in lumber with the increase of the diameter of the logs for both species.

Keywords: Eucalypt; log end splits; utilization of raw material; sawmill.
\end{abstract}

\section{INTRODUÇÃO}

Segundo dados do Anuário Estatístico da Associação Brasileira de Produtores de Florestas Plantadas (ABRAF, 2013), a área ocupada por plantios florestais de eucalipto e pínus no Brasil totalizou 6.664.812 ha em 2012, sendo 76,6\% correspondentes à área de plantios de Eucalyptus e 23,4\% aos plantios de Pinus. Em outro relatório da associação (ABRAF, 2012), é citado que no ano de 2011 foram consumidos no Brasil 170,1 milhões de metros cúbicos de madeira proveniente de plantios florestais, dos quais 117,6 milhões de metros cúbicos eram de eucalipto, utilizado nos diferentes segmentos da indústria da indústria de base florestal. Entretanto, segundo Müller (2013), a produção de madeira serrada de eucalipto

FLORESTA, Curitiba, PR, v. 45, n. 2, p. 241 - 250, abr. / jun. 2015.

Cunha, A. B. da et al.

ISSN eletrônico 1982-4688 / ISSN impresso 0015-3826

241

DOI: $10.5380 /$ rf.v45i2.32570 
ainda é pequena, embora acredite-se que em médio prazo essa tendência seja revertida, em função do desenvolvimento de técnicas eficientes de desdobro, secagem e beneficiamento da matéria-prima.

Segundo Martins et al. (2006), o Eucalyptus grandis é o mais plantado no mundo, devido às características silviculturais desejáveis e a aplicabilidade da madeira para diversos fins, aliada à grande variabilidade genética e à facilidade de aquisição de sementes em quantidade e qualidade. Entretanto, de acordo com Lima (2003), as madeiras serradas produzidas através de reflorestamentos de Eucalyptus apresentam certas características, tais como rachaduras de topo de toras, rachaduras de extremidades das tábuas e empenamento nas peças, que diminuem o aproveitamento da madeira. Essas características são oriundas dos efeitos da tensão de crescimento, que são liberadas quando das operações de derrubada das árvores, armazenamento, traçamento e processamento das toras.

Em trabalho realizado por Silva et al. (1997), em que os autores testaram o comportamento do Eucalyptus grandis mediante as principais operações de usinagem, concluiu-se que a referida madeira comportou-se muito bem, indicando um alto potencial para o setor de madeira serrada, principalmente o setor moveleiro. Segundo Simula e Tissari (1998), o E. grandis é considerado entre os melhores Eucalyptus para diversos usos e movelaria, não demonstrando dificuldade de usinagem e apresentando boa superfície quando aplainado. Rocha (2000) aponta que a madeira do E. grandis proporciona uma boa linha de cola e recebe pintura e brilho prontamente, porém, quanto à aceitação de pregos, as peças pregam bem, mas estão mais sujeitas a rachaduras que as peças de Pinus.

De acordo com Longo et al. (2013), devido ao clima frio que a região serrana de Santa Catarina apresenta, a espécie que mais está sendo comercializada é o Eucalyptus dunnii Maiden, mas estudos vêm buscando alternativas em função de a madeira sólida apresentar grande quantidade de rachaduras, colapsos e empenamentos. Dessa forma, uma espécie que já está recebendo atenção e sendo estudada, devido ao seu potencial característico de sobreviver em baixas temperaturas, é o Eucalyptus benthamii Maiden et Cambage (NISGOSKI et al., 1998).

O E. benthamii é uma espécie da Austrália recentemente introduzida, que apresenta rápido crescimento e excelente forma de fuste. Se plantada em época adequada, não é danificada por geadas severas (DUQUE SILVA et al., 2012). Segundo Higa (2003), o E. benthamii possui uma madeira dimensionalmente instável, com índices elevados de retratibilidade, os quais explicam a alta intensidade de defeitos de processo observados no desdobro e na secagem, mesmo se esta última for realizada em condições amenas, com temperatura ambiente e à sombra. Assim, Higa et al. (2000) alertam que a espécie é adequada para a produção de lenha, carvão, estacas, postes e moirões, porém não é recomendada para fins de serraria.

Dessa forma, pode-se afirmar que é de fundamental importância o estudo da espécie para a utilização como madeira serrada, pois, conforme Rocha e Tomaseli (2002), a utilização de espécies do gênero Eucalyptus como fonte de matéria-prima para serrarias vem, cada vez mais, tornando-se uma interessante alternativa para as indústrias do setor. Porém a maioria das espécies desse gênero apresentam algumas características intrínsecas à madeira que dificultam o seu processamento em serrarias. Entre elas destacam-se as tensões de crescimento, as quais se manifestam na forma de rachadura de topo e empenamentos. Lima et al. (2002) citam que a mensuração das rachaduras nas extremidades das toras é considerada um método indireto na avaliação das tensões de crescimento, podendo em alguns casos ser utilizada como indicador de seleção de árvores para serraria, pela importância que desempenham.

De acordo com Ferreira et al. (2004), a madeira serrada de Eucalyptus exige cuidados no desdobro e na secagem, porque, além da presença de tensões internas de crescimento, suas propriedades físicas e mecânicas são heterogêneas. Segundo o mesmo autor, esses aspectos são os principais responsáveis pelos baixos rendimentos no processamento da madeira, devido à tendência ao rachamento das toras antes e durante o seu desdobro, pelo cerne quebradiço e pelas deformações que surgem na madeira serrada durante o processo de secagem.

Os mesmos autores explicam que, para reduzir os defeitos oriundos das tensões de crescimento, diversas técnicas de desdobro têm sido utilizadas, sendo necessárias também outras ações conjuntas, como melhoramento genético e manejo florestal. Entre os métodos de desdobro, os mais comuns são o paralelo, o radial e o simétrico ou alternado. Segundo Murara Júnior et al. (2005), a técnica de desdobro adotada, a qualidade da matéria-prima e as características dos equipamentos utilizados deverão garantir um rendimento adequado e uma boa qualidade da madeira serrada. Características externas (conicidade, curvatura e achatamento) e internas (tensões de crescimento, excentricidade da medula e rachaduras) das toras são determinantes para se obter qualidade e rendimento satisfatórios (FERREIRA et al., 2004). 
Outro fator de difícil controle na qualidade da madeira serrada de espécies do gênero Eucalyptus é a variabilidade intraespecífica. Essa variabilidade não controlável ou previsível em matérias-primas não clonais expõe os aspectos negativos das propriedades físicas e mecânicas da madeira, além de comprometer quesitos mercadológicos demandados, tais como uniformidade na textura, cor, padronagem etc. (BULHÕES et al., 1995).

Rocha (2000) aponta que existem várias técnicas que podem ser adotadas, tanto na obtenção e preparo das toras como no desdobro, para reduzir as manifestações das tensões de crescimento na obtenção da madeira serrada. Tratando-se da redução das tensões de crescimento quando a árvore será abatida, pode-se destacar a técnica de anelamento da árvore antes de sua derrubada e traçamento, armazenamento na sombra e uso de conectores tipo "gang nail" nas extremidades das toras, entre outros. Já para redução de rachaduras de topo, podem-se usar como alternativas o bloqueamento da lignina, o selamento de topo e o armazenamento de toras sob aspersão.

Estudos indicam que é possível minimizar os efeitos das tensões internas, mas não eliminá-los (OLIVEIRA, 1999). Tais defeitos dificultam e podem inviabilizar a utilização do eucalipto para madeira serrada se não corrigidos a tempo.

O objetivo do presente trabalho foi determinar o aproveitamento da matéria-prima de Eucalyptus benthamii Maiden et Cambage em madeira serrada no processo de desdobro tangencial e radial, bem como compará-lo com o Eucalyptus grandis Hill ex Maiden. Ao mesmo tempo, determinar a porcentagem de rachadura de topo das toras.

\section{MATERIAL E MÉTODOS}

As toras utilizadas no experimento foram provenientes da empresa Klabin, sendo que o reflorestamento com Eucalyptus benthamii estava localizado na cidade de Palmeira, SC, e o de E. grandis na cidade de Telêmaco Borba, PR, ambos plantados com espaçamento 2,5 x 2,5 m e com 13 anos de idade. O processo de derrubada e traçamento das árvores foram feitos de forma mecanizada, por equipe da empresa mencionada, e o desdobro realizado na Madepar Indústria e Comércio de Madeiras Ltda., em Lages (SC), o qual será descrito posteriormente. É importante destacar que as toras ficaram armazenadas na floresta durante 20 dias e no pátio da empresa por mais 15 dias.

Para a realização das atividades, foram utilizadas 240 toras com comprimento médio de $2,45 \mathrm{~m}$ e diâmetro variando entre 20 e $30 \mathrm{~cm}$. Assim, foram estabelecidas duas classes diamétricas, 20 a $25 \mathrm{~cm}$ e 25,01 a $30 \mathrm{~cm}$. Para a determinação da porcentagem de rachaduras, foram analisadas somente 40 toras por espécie, sendo 20 para cada classe diamétrica, enquanto que para a determinação do rendimento de matéria-prima no processo de desdobro foram utilizadas todas as toras, as quais foram divididas por espécie (120 para cada), por classe diamétrica (60 para cada) e por sistema de desdobro, tangencial e radial, respectivamente (30 toras por sistema, sendo 10 em cada repetição).

\section{Índice de rachadura de topo das toras}

A determinação do índice de rachadura das toras foi feita de forma visual, sendo atribuído um conceito (baixo, médio ou alto) baseado no comprimento, na largura e na profundidade da rachadura, conforme apresentado na figura 1.
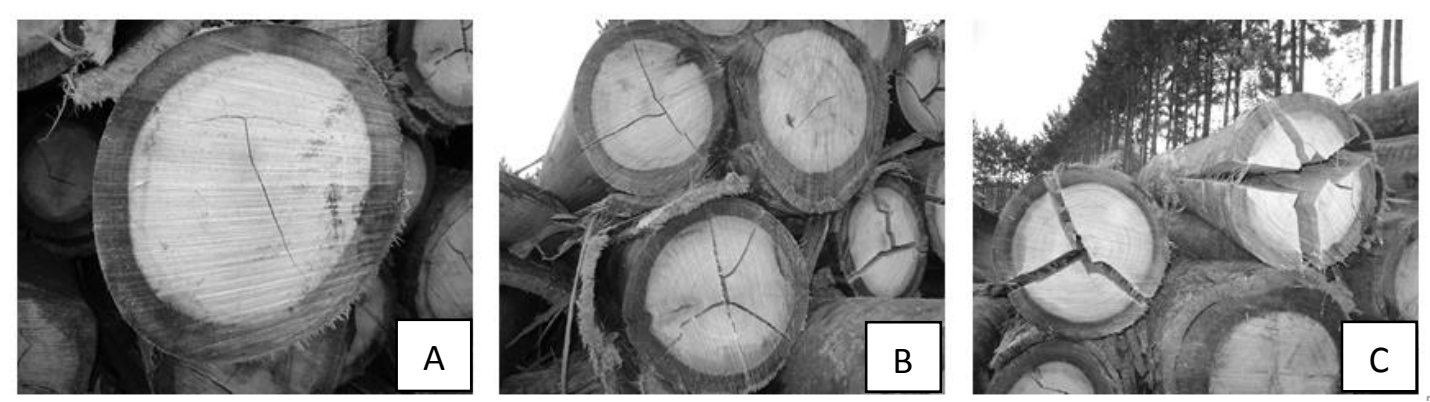

Figura 1. Análise visual da rachadura para determinação do conceito. A: baixo; B: médio; C: alto. Figure 1. Visual analysis of the crack to determine the concept. A: low; B: medium C: high.

FLORESTA, Curitiba, PR, v. 45, n. 2, p. 241 - 250, abr. / jun. 2015.

Cunha, A. B. da et al.

ISSN eletrônico 1982-4688 / ISSN impresso 0015-3826 


\section{Rendimento de madeira serrada}

Foi obtido pela relação entre o somatório do volume das peças de madeira serrada e o volume das toras de cada repetição, expresso em porcentagem. Para a determinação do volume das toras, utilizouse o método de Smalian, sendo medidos os diâmetros das duas pontas da tora, com auxílio de uma suta, e o comprimento ao longo do eixo, com uma trena. Na determinação do volume de madeira serrada, mediuse a espessura de cada peça em cinco pontos, a largura em dois e o comprimento na parte central. Mensuraram-se também as rachaduras existentes nas quatro faces da peça e os locais onde havia necessidade de fazer um destopo, pela presença de nós, esmoado ou pelo desbitolamento (diferença de largura entre a porção maior da peça e a parte considerada). Dessa forma, obteve-se o rendimento:

- bruto do processo: considerando que a peça não apresentava defeitos naturais e/ou de processo, os quais serão retirados em processo nas operações subsequentes, como refilo e destopo;

- sem as partes rachadas: considerando a retirada das rachaduras no destopo e/ou refilo das peças, porém mantendo nas peças os demais defeitos, para evidenciar a influência da rachadura de forma isolada no desdobro;

- sem as partes a serem destopadas: considerando a retirada dos demais defeitos, que também são retirados em operações de destopo no desdobro secundário. Nessa análise, as rachaduras não são consideradas como destopo.

- líquido: considerando as peças sem as partes rachadas e sem as partes destopadas, ou seja, o que realmente seria enviado para a secagem ou comercializado pela empresa. Esse rendimento pode ser considerado o real do processo, em função da retirada de todos os defeitos que causam a perda da qualidade das peças de madeira serrada. sequência.

Os sistemas de desdobro aplicados às toras estão apresentados na figura 2 e descritos na
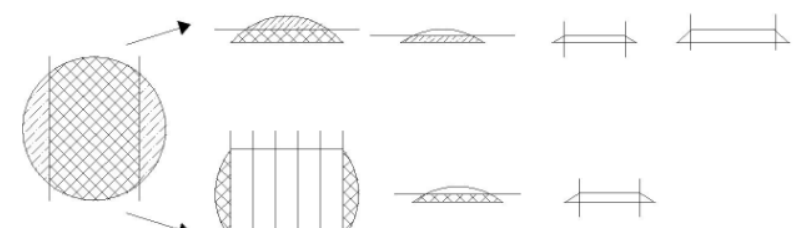

(B)
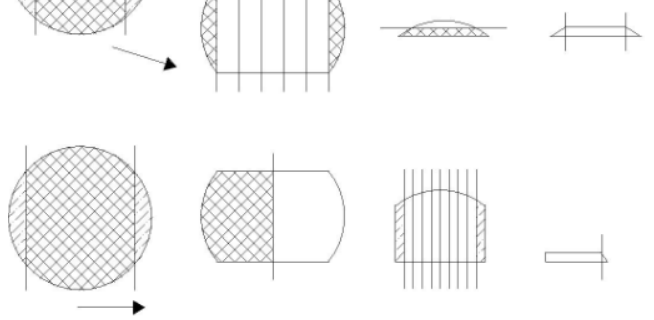

Figura 2. Sistemas de desdobro aplicados. (A) tangencial; (B) radial.

Figure 2. Systems sawing applied. (A) tangential, (B) radial.

- Sistema de desdobro tangencial (Figura 2A): as toras, no processo de desdobro tangencial, passaram por uma serra fita simples, onde foi feito um corte alternado, retirando-se duas costaneiras. O semibloco central foi direcionado para uma serra circular múltipla de dois eixos, para a obtenção das peças de madeira serrada. Caso as peças apresentassem defeitos em suas laterais, eram passadas em uma refiladeira. Já as costaneiras foram reaproveitadas em uma sequência de duas serras fitas horizontais e por uma serra circular dupla, para a realização do refilo.

- Sistema de desdobro radial (Figura 2B): foram retiradas duas costaneiras de dimensão reduzida na serra fita simples, para que não houvesse o corte na parte central da tora no primeiro momento, de forma a tentar minimizar o efeito das tensões de crescimento nas toras de eucalipto. Posteriormente, o semibloco foi aberto ao meio no mesmo equipamento, sendo as duas partes passadas por uma serra circular múltipla de dois eixos e por uma refiladeira, para padronizar as bordas. As costaneiras provenientes dos dois primeiros cortes não foram aproveitadas.

\section{Análise estatística}

$\mathrm{Na}$ análise do índice de rachadura de topo, foi adotado como parâmetro de comparação entre os tratamentos a porcentagem de toras que apresentaram os conceitos aplicados (baixo, médio e alto). Já na 
avaliação do rendimento no processo de desdobro, adotou-se delineamento inteiramente casualizado, com arranjo fatorial $2 \times 2 \times 2$, sendo espécie, classe diamétrica e método de desdobro, respectivamente. Para testar a distribuição normal entre os dados, foi aplicado o teste de Shapiro-Wilk. Após ser comprovada a existência de homogeneidade dos dados, foi aplicada a Análise de Variância. Havendo rejeição da hipótese de igualdade, foi aplicado o teste de Tukey a 95\% de probabilidade, para comparação de médias. O programa estatístico utilizado para a análise foi o SPSS.

\section{RESULTADOS E DISCUSSÕES}

\section{Índice de rachaduras de topo das toras}

$\mathrm{Na}$ figura 3 está apresentada a porcentagem de rachaduras de topo das toras de E. benthamii e E. grandis, em que pode ser observado que a maioria das toras das duas espécies apresentaram índice médio de rachaduras, com porcentagens de $43,43 \%$ e $62,92 \%$, respectivamente. Já índice alto foi apresentado por somente $19,05 \%$ das toras de E. benthamii e não foi evidenciado nas toras de E. grandis.

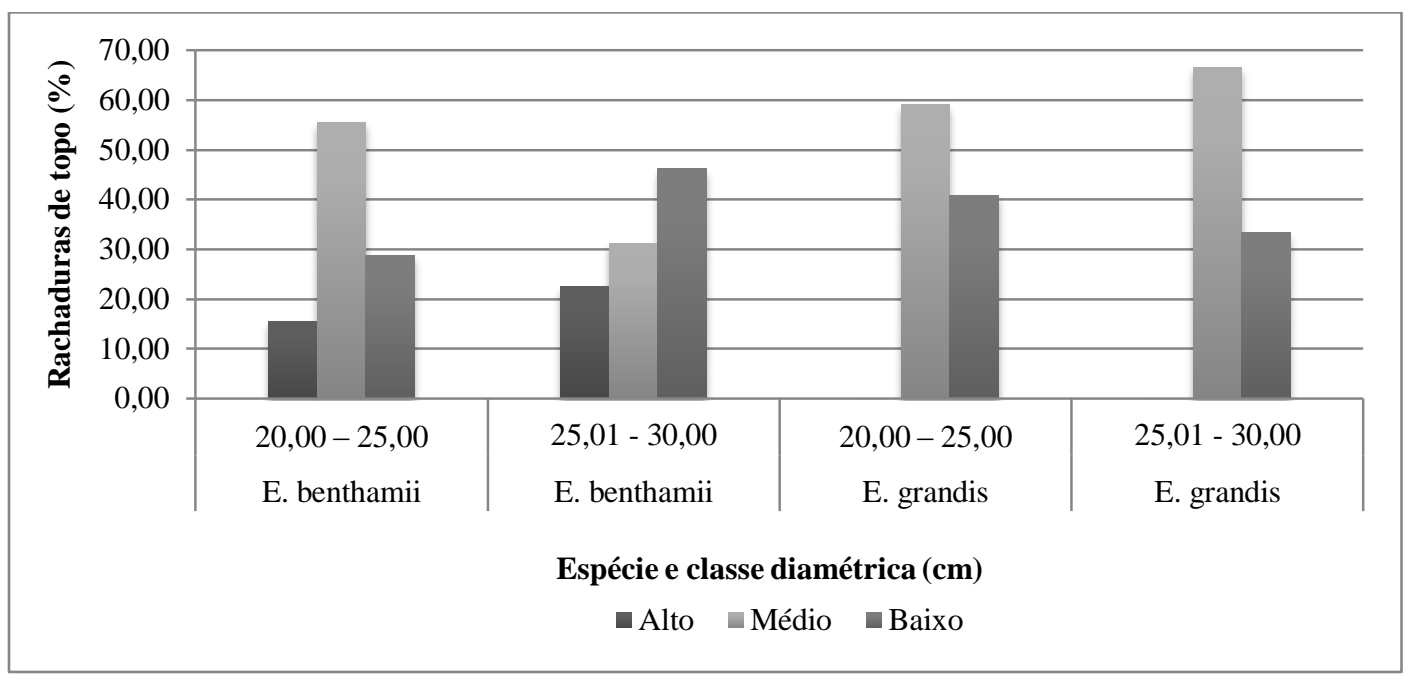

Figura 3. Porcentagem de rachadura de topo nas toras por espécie e classe diamétrica.

Figure 3. Percentage of log end splits of the logs by species and diameter class.

Comparando-se as classes diamétricas do E. benthamii, observa-se que a porcentagem de toras que apresentaram índice de rachaduras médio diminuiu com o aumento do diâmetro das toras, de 55,6\% para $31,5 \%$. Em contrapartida, as toras com conceito baixo aumentaram de forma acentuada, de $28,80 \%$ para $46,25 \%$. Já para o E. grandis, a figura 3 mostra que a porcentagem de toras com rachaduras com conceito médio aumentou com o aumento do diâmetro das toras.

Muller (2013), estudando a porcentagem de rachaduras de toras de E.benthamii com 6 anos de idade em duas classes diamétricas ( 20 a $25 \mathrm{~cm}$ e 25,1 a $30 \mathrm{~cm}$ ), observou que as rachaduras de topo foram frequentes em todas as toras avaliadas. Esses resultados estão coerentes com os encontrados no presente estudo, mesmo com a diferença de idade das árvores estudadas. No entanto, não foi verificada a mesma homogeneidade da intensidade desse defeito para as toras selecionadas entre os diferentes tratamentos.

Hornburg (2012) analisou a qualidade das toras de seis espécies de Eucalyptus cultivadas no litoral de Santa Catarina (Corymbia torelliana F. Muell., E. cloeziana F. Muell., E. resinifera Sm., E. pilularis $\mathrm{Sm}$., E. grandis W. Hill ex Maiden e do híbrido E. grandis W. Hill ex Maiden x E. urophylla S. T. Blake) e verificou que houve uma tendência de as rachaduras aumentarem com o aumento do diâmetro das toras. Essa constatação também foi verificada por Chafe (1995) e Malan (1984). Segundo Calonego e Severo (2005a), uma das possíveis causas das toras de maiores diâmetros apresentarem maiores rachaduras é, teoricamente, a presença dos lenhos juvenil e adulto nessas toras, além da presença, muitas vezes, do cerne quebradiço na região próxima da medula. No entanto, no presente estudo essa 
constatação foi verificada somente para as toras de E. grandis, enquanto as toras de E. benthamii tiveram uma tendência inversa.

Assim, acredita-se que os fatores que podem ter influenciado na ocorrência das rachaduras de topo nas toras foram a espécie, as tensões de crescimento, a idade dos reflorestamentos, a forma de derrubada das árvores e o tempo de armazenamento, tanto na floresta quanto no pátio da empresa.

Segundo Hillis e Brown (1984), as tensões internas de crescimento são liberadas durante a colheita das árvores, ou até uma semana depois, provocando a formação de rachaduras no topo das toras. Quanto ao tempo de armazenamento, Aguiar e Jankowsky (1986) afirmam que a exposição das toras ao ar leva ao imediato processo de secagem, em que a retração da parte externa da tora não é acompanhada pela mais interna, que continua com maior teor de umidade, surgindo as tensões internas, que, tornando-se superiores à resistência da madeira, provocam o aparecimento das rachaduras. Segundo Barnacle e Gottstein (1968), as tensões de secagem interagem com as tensões de crescimento para produzir rachaduras nos topos. Esses dois fatos, colheira mecanizada e tempo de armazenamento das toras prolongado (35 dias), podem ter contribuído para o aumento do índice de rachaduras das toras nas duas espécies estudadas.

\section{Rendimento do processo de desdobro}

As porcentagens referentes ao rendimento do processo de desdobro do E. benthamii e do E. grandis por meio dos sistemas tangencial e radial estão apresentadas na tabela 1, onde se pode observar que o desdobro pelo método tangencial apresentou maior rendimento em todas os tratamentos, exceto no composto pelo Eucalyptus benthamii e pela classe diamétrica de 25,01-30,0 cm, no qual os rendimentos obtidos pelos métodos tangencial e radial foram equivalentes.

Tabela 1. Rendimento do processo em dois sistemas de desdobro.

Table 1. Process yield in two sawing systems.

\begin{tabular}{|c|c|c|c|c|c|c|}
\hline & $\begin{array}{c}\text { Classe } \\
\text { diamétrica } \\
(\mathrm{cm})\end{array}$ & $\begin{array}{l}\text { Sistema } \\
\text { de } \\
\text { desdobro }\end{array}$ & $\begin{array}{c}\text { Sem } \\
\text { defeito } \\
(\%)\end{array}$ & $\begin{array}{c}\text { Sem } \\
\text { rachaduras } \\
(\%)\end{array}$ & $\begin{array}{c}\text { Sem } \\
\text { destopos } \\
(\%) \\
\end{array}$ & $\begin{array}{c}\text { Sem rachaduras e } \\
\text { destopos } \\
(\%)\end{array}$ \\
\hline \multirow{4}{*}{ E. benthamii } & \multirow{2}{*}{$20-25$} & Tangencial & $62,37 \mathrm{a}$ & $51,55 \mathrm{bc}$ & $58,48 \mathrm{a}$ & $48,69 \mathrm{bc}$ \\
\hline & & Radial & $47,05 \mathrm{c}$ & $41,35 \mathrm{~d}$ & $41,37 \mathrm{c}$ & $36,79 \mathrm{e}$ \\
\hline & \multirow{2}{*}{$25,1-30$} & Tangencial & $53,57 \mathrm{~b}$ & $42,92 \mathrm{de}$ & $49,00 \mathrm{~b}$ & $39,31 \mathrm{de}$ \\
\hline & & Radial & 48,84 bc & $43,17 \mathrm{de}$ & $43,63 \mathrm{bc}$ & $39,05 \mathrm{de}$ \\
\hline \multirow{4}{*}{ E. grandis } & \multirow{2}{*}{$20-25$} & Tangencial & $66,40 \mathrm{a}$ & $60,60 \mathrm{a}$ & $62,10 \mathrm{a}$ & 56,70 a \\
\hline & & Radial & $50,10 \mathrm{bc}$ & $47,60 \mathrm{~cd}$ & $45,20 \mathrm{bc}$ & $43,30 \mathrm{~cd}$ \\
\hline & \multirow{2}{*}{$25,1-30$} & Tangencial & $61,40 \mathrm{a}$ & $55,40 \mathrm{ab}$ & $57,60 \mathrm{a}$ & $51,90 \mathrm{ab}$ \\
\hline & & Radial & $47,20 \mathrm{c}$ & $44,60 \mathrm{de}$ & $43,70 \mathrm{bc}$ & $41,60 \mathrm{de}$ \\
\hline
\end{tabular}

Médias seguidas de uma mesma letra em uma mesma coluna não diferem estatisticamente entre si pelo teste de Tukey ao nível de $5 \%$ de probabilidade.

Realizando-se uma análise mais abrangente do rendimento bruto do processo de desdobro, ou seja, considerando que a madeira não apresentasse nenhum tipo de defeito, verifica-se que o $E$. grandis apresentou um maior rendimento médio (56,28\%), quando comparado ao E. benthamii (52,96\%). Já na análise das classes diamétricas, observa-se que a classe inferior $(20-25 \mathrm{~cm})$ mostrou-se mais produtiva $(56,48 \%)$ que a classe superior $(52,75 \%)$. Ao mesmo tempo, caracterizando-se somente os sistemas de desdobro, obtêm-se $60,94 \%$ para o tangencial e $48,30 \%$ para o radial.

No entanto, quando realizada a análise estatística que englobou as duas espécies, bem como as classes diamétricas e os sistemas de desdobro, observa-se que os melhores tratamentos foram os que adotaram o método tangencial de desdobro para as duas espécies, independentemente da classe diamétrica, com exceção da classe superior do E. benthamii, que não apresentou diferença entre os métodos tangencial e radial. Segundo Vermaas (1995), o desdobro tangencial é preferido na Austrália por apresentar melhor desenho e maior rendimento em madeira serrada, fato que também foi verificado no presente estudo. Rocha (2002) destaca que esse método apresenta também a vantagem de permitir que o empenamento apresentado pelas tábuas seja mais facilmente corrigido do que o apresentado pelas tábuas radiais.

Com relação ao desdobro radial, verificou-se que as peças apresentavam dimensão reduzida em largura quando comparadas com as peças obtidas pelo desdobro tangencial. Dessa forma, segundo Rocha 
(2000), as peças obtidas pelo desdobro radial de toras com diâmetro entre 20 e $30 \mathrm{~cm}$ são indicadas para a fabricação de painéis, em função da variação no comprimento e larguras reduzidas. Já as peças obtidas pelo desdobro tangencial podem ter usos mais variados (ROCHA, 2000). Segundo Vital (2008), mesmo com as dimensões reduzidas, as peças radiais proporcionam melhor aspecto, especialmente na madeira de folhosas, expondo os seus raios; menor contração em largura, o que contribui para a menor movimentação em serviço e menor susceptibilidade ao encanoamento. Além disso, na ocorrência das bolsas de quino, comumente encontradas em eucalipto, as tábuas apresentam-se com linha finas, sendo aceitáveis quanto ao aspecto.

Comparando-se o rendimento percentual bruto do processo com o rendimento sem considerar as partes rachadas das peças, pode-se observar que os tratamentos mais influenciados foram os que contemplavam o $E$. benthamii com desdobro tangencial para as duas classes diamétricas, os quais perderam $10,82 \%$ e $10,65 \%$ para a classe inferior e para a superior, respectivamente. Já os menos influenciados pelas rachaduras foram os que englobavam o E. grandis e o desdobro radial nas duas classes diamétricas. Entretanto, quando enfocado somente o rendimento do processo sem as partes rachadas, as toras de $E$. grandis desdobradas pelo método tangencial figuram como os melhores tratamentos.

De forma geral, pode-se dizer que o $E$. benthamii perdeu em média $8,21 \%$ de rendimento devido às rachaduras e o $E$. grandis, 4,07\%. Tomando-se como referência o trabalho desenvolvido por Muller (2013), que encontrou, no desdobro de toras de E. benthamii com 6 anos de idade, em peças de madeira serrada, rendimento médio de $28,88 \%$ para o tangencial na classe de 20 a $24,9 \mathrm{~cm}$ e $32,46 \%$ na classe diamétrica de 25 a $29,39 \mathrm{~cm}$, pode-se verificar que os valores estão abaixo dos encontrados no presente estudo. $\mathrm{O}$ fator que provavelmente por ter contribuído para a grande diferença dos rendimentos é a idade reduzida das toras que foram desdobradas pela autora no estudo supracitado.

Quando abordado de forma isolada o rendimento do processo de desdobro sem considerar as partes a serem destopadas das peças, observa-se que os melhores tratamentos são os mesmos do rendimento bruto do processo, ou seja, todos os que contemplaram o desdobro tangencial, com exceção do E. benthamii na classe superior. Portanto, como os resultados tiveram a mesma tendência, pode-se dizer que a perda média em função do destopo foi de 4,60\%, o qual foi proveniente principalmente do desbitolamento das peças em largura.

Quanto ao rendimento líquido do processo, ou seja, considerando somente as peças de madeira serrada que seriam comercializadas ou enviadas para a secagem, a partir dos lotes de toras considerados, pode-se dizer que as toras de E. grandis desdobradas pelo método tangencial foram os melhores tratamentos do estudo, com rendimentos de $56,70 \%$ e $51,90 \%$ para as classes inferior e superior, respectivamente.

De acordo com Rocha e Tomaselli (2001), o rendimento do processo de desdobro varia de 45 a $55 \%$ para folhosas, sendo afetado pela qualidade das toras e dos equipamentos, pelas técnicas de desdobro e pela qualificação profissional dos operários. Comparando com os resultados encontrados no presente estudo, observa-se que somente dois tratamentos ficaram dentro da faixa determinada pelos autores, sendo o primeiro composto por toras de $E$. benthamii na classe diamétrica de 20 a $25 \mathrm{~cm}$ e o segundo com E. grandis na classe 25 a $30 \mathrm{~cm}$. Cabe salientar que todos os tratamentos que envolveram método de desdobro radial ficaram abaixo do limite inferior (45\%), o que é devido principalmente ao número de cortes executados no processo de resserragem para a definição da espessura das peças e do refilo para regularização das bordas. O tratamento que envolveu o $E$. grandis, desdobro tangencial e classe diamétrica de 20 a $25 \mathrm{~cm}$ foi o único que ficou acima do limite superior (55\%), o que foi consequência da baixa quantidade de rachaduras e defeitos naturais e/ou de processo presentes nas peças.

Se forem comparadas somente as espécies, encontra-se rendimento de 40,96\% para o E. benthamii e 48,37\% para o E. grandis. Priest (1982), desdobrando E. grandis com 24 anos, diâmetro variando de 38 a $51 \mathrm{~cm}$, encontrou rendimento por volta de 59\%. Monteiro et al. (2012), estudando esse mesmo gênero, obteve rendimento de $43,8 \%$ para toras com diâmetro médio de $34 \mathrm{~cm}$. Em ambos os estudos, foram encontrados rendimentos superiores ao do E. benthamii, o que pode ser atribuído às características da espécie, ao diâmetro das toras, ao sistema de desdobro e às dimensões das peças finais. Todavia, o rendimento das toras de $E$. grandis do presente estudo apresentou rendimento superior ao de Monteiro et al. (2012) e menor que o de Priest (1982). No segundo caso, pode-se apontar a influência da idade no melhor aproveitamento das toras.

No que tange às classes diamétricas, verifica-se que o $E$. benthamii apresentou rendimento líquido médio de $42,74 \%$ para a classe inferior e $39,18 \%$ para a superior. Já para o $E$. grandis, obteve-se $50 \%$ para a inferior e $46,75 \%$ para a superior. Dessa forma, observa-se que houve uma redução do

FLORESTA, Curitiba, PR, v. 45, n. 2, p. 241 - 250, abr. / jun. 2015.

Cunha, A. B. da et al.

ISSN eletrônico 1982-4688 / ISSN impresso 0015-3826

DOI: $10.5380 /$ rf.v45i2.32570 
rendimento com o aumento do diâmetro das toras para as duas espécies. Calonego e Severo (2005b), estudando o efeito do diâmetro de toras na manifestação das tensões de crescimento em tábuas de E. grandis, concluíram que quanto maior é o diâmetro das toras, maiores são os índices de comprimento de rachaduras e, assim, menores são os rendimentos. Del Menezzi e Nahuz (1998b), analisando os resultados obtidos no desdobro da primeira e segunda tora, observaram redução do rendimento médio com a elevação do diâmetro médio das toras. Os autores salientam que esses resultados não são coerentes com a maioria dos estudos, porém indicam que, além do diâmetro, existem outros fatores que interferem no rendimento em madeira serrada, como a qualidade da tora, a técnica de desdobro empregada e os equipamentos utilizados nas operações de corte. Santos (2010), avaliando o rendimento do desdobro de toras de E. camaldulensis com 11 anos de idade, encontrou rendimento de 35,33\% para a classe diamétrica de 14 a $19,9 \mathrm{~cm}$, e de $40,13 \%$ de rendimento para E. urophylla com 10 anos de idade e diâmetros variando entre 20 e $25 \mathrm{~cm}$.

Quanto aos dois sistemas de desdobro aplicados, observa-se que o rendimento obtido por meio do método tangencial para o $E$. benthamii foi de $44 \%$, e para o radial, 37,92\%. Já para $E$. grandis, o rendimento para o tangencial foi de $54,30 \%$ e de $42,45 \%$ no radial. Para $E$. benthamii, os valores encontrados são praticamente equivalentes aos encontrados por Muller (2013), que, trabalhando com E. benthamii com 5 anos de idade e com o mesmo sistema de desdobro, encontrou 41,91\% para o método tangencial e 36,73\% para o radial. Rocha (2009), estudando E. grandis com 12 anos, diâmetros entre 19 e 24 cm, encontrou rendimentos médios de $45,71 \%$ e 50,41\% para o desdobro tangencial e radial, respectivamente. É importante destacar que os rendimentos apresentados pelo autor são em peças secas, portanto não derivados somente do processo de desdobro, como o objeto do presente estudo. Assim, pode-se dizer que, após o processo de secagem, o rendimento irá ser alterado, bem como a qualidade das peças, tendo vista que as peças tangenciais são mais estáveis no desdobro e mais instáveis durante o processo de secagem.

\section{CONCLUSÃO}

- A presença de rachaduras de topo foi frequente em todas as toras de E. benthamii e E. grandis avaliadas, porém com intensidades diferenciadas. A presença das rachaduras de topo diminuiu com o aumento do diâmetro nas toras de E. benthamii, porém aumentou nas toras de E. grandis.

- O desdobro das toras de E. benthamii e E. grandis pelo método tangencial apresentou maior rendimento de madeira serrada em relação ao radial para as duas classes diamétricas, com exceção do aproveitamento da matéria-prima de Eucalyptus benthamii da classe diamétrica superior.

- O rendimento médio bruto do processo de desdobro foi de 56,27\% para o E. grandis e de 52,96\% para o E. benthamii. Considerando a retirada das partes rachadas das peças, observou-se que os tratamentos que apresentaram maior redução em termos de rendimento foram os compostos pelo E. benthamii com desdobro tangencial e pelas duas classes diamétricas, com diminuição de $10,82 \%$ e $10,65 \%$ para a classe inferior e para a superior.

- O destopo das peças de madeira serrada das duas espécies estudadas foi derivado principalmente do desbitolamento no momento do desdobro, com redução média de 4,60\% do rendimento bruto.

- No rendimento líquido do processo, observou-se que as toras de E. grandis desdobradas pelo método tangencial foram os melhores tratamentos do estudo. Quanto às classes diamétricas, houve uma redução do rendimento com o aumento do diâmetro das toras para as duas espécies.

\section{AGRADECIMENTOS}

Os autores expressam os seus agradecimentos à Klabin (Unidade Otacílio), pela doação da matéria-prima utilizada nesta pesquisa; e à Madepar Indústria e Comércio de Madeiras Ltda., pelo apoio na realização do processo de desdobro.

\section{REFERÊNCIAS}

ASSOCIAÇÃO BRASILEIRA DE PRODUTORES DE FLORESTA PLANTADA (ABRAF). Anuário Estatístico da ABRAF 2013 - Ano Base 2012. Brasília, 2013, p. 142.

Anuário Estatístico da ABRAF 2012 - Ano Base 2011. Brasília, 2012, p. 150. 
AGUIAR, O. J. R.; JANKOWSKI, I. P. Prevenção e controle das rachaduras de topo em tora de Eucalyptus grandis Hill ex Maiden. Scientia Forestalis, Piracicaba, n. 33, p. 39-46, 1986.

ALFONSO, V. A. Caracterização anatômica do lenho e da casca das principais espécies de Eucalyptus L. Herit. cultivadas no Brasil. 188 p. Tese (Doutorado em Botânica) - Instituto de Biociências da Universidade de São Paulo, São Paulo, 1987.

BARNACLE, J. E.; GOTTSTEIN, J. W. Control of end-splitting in round timber: a promising new method. Forest Products Technical Notes. Melbourne: CSIRO, 1968, 4 p.

BULHÕES, O. C. A.; CERQUEIRA, C. C.; ALBENY, M. M.; JORDY FILHO, S. Do planejamento e critérios adotados pela CVRD para identificação de clones de E. grandis para serraria. Seminário Internacional de Utilização da Madeira de Eucalipto para Serraria. São Paulo, 1995. p. 42-49.

CALONEGO, F. W.; SEVERO, E. T. D. Efeito da vaporização de toras na redução dos defeitos associados a tensões de crescimento de Eucalyptus grandis. Ciência Florestal, Santa Maria, v. 15, n. 4, p. 431-440, 2005a.

Efeito do diâmetro das toras e magnitude das tensões de crescimento de Eucalyptus grandis. Energia na Agricultura, Botucatu, v. 20, n. 2, p. 53-65, 2005b.

CHAFE, S. C. Variation in longitudinal growth stress with height in trees of Eucalyptus nitens Maiden. Australian Forest Research, Canberra, v. 15, n. 1, p. 51-55, 1985.

DEL MENEZZI, C. H. S.; NAHUZ, M. A. R. Comportamento de Eucalyptus grandis no desdobro. Árvore, Viçosa, v. 22, n. 4, p. 563-571, 1998.

DUQUE SILVA, L.; HIGA, A. R.; GARCIA, J. N. Desafios do uso da madeira de Eucalyptus benthamii para serraria. Silvicultura e Melhoramento Genético de Eucalyptus benthamii. 1. ed. Curitiba: FUPEF do Paraná, 2012, v. 1, p. 119-140.

FERREIRA, S.; LIMA, J. T.; ROSADO, S. C. S.; TRUGILHO, P. F. Influência de métodos de desdobro tangenciais no rendimento e na qualidade da madeira de clones de Eucalyptus spp. Cerne, Lavras, v. 10, n. 1, p. 10-21, 2004.

GALVÃO, A. P. M.; JANKOWSKY, I. P. Secagem racional da madeira. Nobel, 1985, p. 107.

GONÇALVES, F. G.; OLIVEIRA, J. T. S.; SILVA, G. F.; NAPPO, M. E.; TOMAZELO FILHO, M. Parâmetros dendrométricos e correlações com propriedades tecnológicas em um híbrido clonal de Eucalyptus urophylla x Eucalyptus grandis. Árvore, Viçosa, v. 34, n. 5, p. 949-957, 2010.

HASELEIN, C. R.; LOPES, M. de C.; SANTINI, E. J.; LONGHI, S. J.; ROSSO, S.; FERNANDES, D. L. G.; MENEZES, L. F. de. Características tecnológicas da madeira de árvores matrizes de Eucalyptus grandis. Ciência Florestal, Santa Maria, v. 14, n. 2, p. 145-155, 2004.

HIGA, R. C. V.; PEREIRA, J. C. D. Usos potenciais do Eucalyptus benthamii Maiden et Cambage. Colombo: Embrapa Florestas, 2003. Comunicado Técnico, n. 100, p. 4.

HIGA, R. C. V.; MORA, A. L.; HIGA, A. R. Plantio de eucalipto na pequena propriedade rural. Colombo: Embrapa Florestas, 2000. Comunicado Técnico, n. 54, p. 31.

HILLIS, W. E.; BROWN, A. G. Eucalyptus of wood production. Austrália: CSIRO, 1984, 434 p.

HORNBURG, K. F.; ELEOTÉRIO, J. E.; BAGATTOLI, T. R.; NICOLETTI, A. L. Qualidade das toras e da madeira serrada de seis espécies de eucalipto cultivadas no litoral de Santa Catarina. Scientia Forestalis, Piracicaba, v. 40, n. 96, p. 463-471, 2012.

LIMA, I. L. Técnicas de corte e derrubada de eucalipto para aliviar rachaduras de topo de toras. Revista Científica Eletrônica de Engenharia Florestal, Garça, ano 1, n. 2, 2003.

LIMA, I. L.; GARCIA, J. N.; PIEDADE, S. M. S. Rachaduras de extremidades de tora e suas implicações nas rachaduras da madeira serrada. Scientia Florestalis, Piracicaba, n. 61, p. 13-24, 2002.

LONGO, B. L.; CUNHA, A. B.; BREHMER, D. R. Influência do teor de adesivo na produção de painéis de partícula de madeira aglomerada de Eucalyptus benthamii. In: I CBCM - CONGRESSO

FLORESTA, Curitiba, PR, v. 45, n. 2, p. 241 - 250, abr. / jun. 2015.

Cunha, A. B. da et al.

ISSN eletrônico 1982-4688 / ISSN impresso 0015-3826

249

DOI: $10.5380 /$ rf.v45i2.32570 
BRASILEIRO DE CIÊNCIA E TECNOLOGIA DA MADEIRA E III SIMPÓSIO DE CIÊNCIA E TECNOLOGIA DA MADEIRA DO RIO DE JANEIRO, 2013, Petrópolis, RJ. Anais... 2013, CD-ROM.

MALAN, F. S. Studies on the phenotipic variation in growth stress intensity and its association with tree and wood properties of South Africa Grow, Eucalyptus grandis (Hill ex Maiden). 1984. Tese (Doutorado em Tecnologia da Madeira) - University of Stellenbosch.

MARTINS, I. S.; MARTINS, R. C. C.; PINHO, D. S. Alternativas de índices de seleção em uma população de Eucalyptus grandis Hill ex Maiden. Cerne, Lavras, v. 12, n. 3, p. 287-291, 2006.

MONTEIRO, T. C.; LIMA, J. T.; TRUGILHO, P. F. Energia armazenada nos resíduos do desdobro de toras de Eucalyptus grandis. Ciência da Madeira (Braz. J. Wood Sci.), Pelotas, v. 3, n. 01, p. 33-42, 2012.

MULLER, B. V. Efeito de sistemas de desdobro na qualidade e rendimento de madeira serrada de Eucalyptus benthamii Maiden et Cambage. 119 f. Dissertação (Mestrado em Tecnologia e Utilização de Produtos Florestais) - Universidade Federal do Paraná, 2013.

MURARA JÚNIOR, M. I.; ROCHA, M. P. da; TIMOFEICZYK JÚNIOR, R. Rendimento em madeira serrada de Pinus taeda para duas metodologias de desdobro. Floresta, Curitiba, v. 35, n. 3, 2005.

NISGOSKI, S.; MUNIZ, G. I. B.; KLOCK, U. Características anatômicas da madeira de Eucalyptus benthamii Maiden et Cambage. Ciência Florestal, Santa Maria, v. 8, n. 1, p. 67-76, 1998.

OLIVEIRA, J. T. da S. Problemas e oportunidades com a utilização da madeira de eucalipto. In: WORKSHOP: Técnicas de Abate, Processamento e Utilização da Madeira de Eucalipto. Viçosa-MG, 22 a 24 de junho de 1999. p. 39-52.

OLIVEIRA, J. T. da S.; HELLMEISTER, J. C.; SIMÕES, J. W.; TOMAZELLO FILHO, M. Caracterização da madeira de sete espécies de eucaliptos para a construção civil: 1- avaliações dendrométricas das árvores. Scientia Forestalis, Piracicaba, n. 56, p. 113-124, 1999.

PRIEST, D. T. The machining properties os Eucalyptus grandis. National Timber Research Institute, Pretoria, 9 p., 1982.

ROCHA, M. P. Técnicas e planejamento em serrarias. Curitiba: Fundação de Pesquisas Florestais do Paraná - FUPEF, série didática n. 01/02, p. 121, 2002.

Eucalyptus grandis Hill ex Maiden e Eucalyptus dunnii Maiden como fontes de matéria-prima para serrarias. 185 f. Tese (Doutorado em Engenharia Florestal) - Setor de Ciências Agrárias, Universidade Federal do Paraná, Curitiba, 2000.

ROCHA, M. P.; TOMASELLI, I. Efeito do modelo de desdobro na qualidade da madeira serrada de Eucalyptus grandis e Eucalyptus dunni. Cerne, Lavras, v. 8, n. 2, p. 73-86, 2002.

Efeito do modelo de corte nas dimensões de madeira serrada de Eucalyptus grandis e Eucalyptus dunnii. Floresta e Ambiente, Seropédica, v. 8, n. 1, p. 94-103, 2001.

SANTOS, I. S.; LIMA, J. T.; SILVA, J. R. M. Avaliação de pisos produzidos a partir de toras de clones de Eucalyptus sp. com pequenos diâmetros. Cerne, Lavras, v. 16, n. 4, p. 473-478, 2010.

SILVA, J. R. M.; MENDES, L. M.; WENZEL, M. K.; TRUGILHO, P. F. Secagem ao ar livre da madeira de Eucalyptus grandis para a produção de móveis. Cerne, Lavras, v. 3 n. 1 p. 170-186, 1997.

SIMULA, M. T.; TISSARI, J. T. Market Prospects for Eucalyptus Solid Wood Products in the European Commun Market. In: $\mathbf{1}^{\mathbf{0}}$ Seminário Internacional sobre Produtos Sólidos de Madeira de Alta Tecnologia e $1^{0}$ Encontro sobre Tecnologias Apropriadas de Desdobro, Secagem e Utilização da Madeira de Eucalipto. Belo Horizonte, 7 a 11 de dezembro de 1998. p. 29-48.

VERMAAS, H. F. Drying eucalypts for quality: material characteristics, pre-drying treatments, drying methods, schedules and optimization of drying quality. In. SEMINÁRIO INTERNACIONAL DE UTILIZAÇÃO DA MADEIRA DE EUCALIPTO PARA SERRARIA. São Paulo, 1995. Anais... Piracicaba: IPEF/IPT, 1995. p. 119-132.

VITAL, B. R. Planejamento e Operação de Serrarias. Editora da UFV, 2008, p. 211. 